\title{
(6) OPEN ACCESS \\ Analysis of British American Tobacco's questionable use of privilege and protected document claims at the Guildford Depository
}

\author{
Eric LeGresley, ${ }^{1}$ Kelley Lee ${ }^{2}$
}

\begin{abstract}
- Additional material is published online only. To view please visit the journal online (http://dx.doi.org/10.1136/ tobaccocontrol-2016-052955).

TTobacco Control Consultant, Ottawa, Ontario, Canada 2Faculty of Health Sciences, Simon Fraser University, Burnaby, British Columbia, Canada
\end{abstract}

Correspondence to Professor Kelley Lee, Faculty of Health Sciences, Simon Fraser University, Blusson Hall, 8888 University Drive, Burnaby, BC, Canada V5A 1S6; kelley_lee@sfu.ca

Received 1 February 2016 Accepted 13 May 2016 Published Online First 27 June 2016

\section{ABSTRACT \\ Background Tobacco companies have a documented history of attempting to hide information from public scrutiny, including inappropriate privilege claims. The 1998 Minnesota Consent Judgement created two depositories to provide public access to discovered documents. Users raised concerns about the access conditions and ongoing integrity of the Guildford Depository collection operated until 2015 by British American Tobacco (BAT). \\ Methods A metadata search of the Legacy Tobacco Documents Library identified inconsistent privilege claims, and duplicates of documents withheld by BAT from public visitors. A review of the validity of claims, for documents obtained through these searches, was conducted against recognised legal definitions of privilege.}

Findings BAT has asserted inappropriate privilege claims over $49 \%$ of the documents reviewed $(n=63)$. The quantity of such claims and consistency of the stated rationale for the privilege claims suggest a concerted effort rather than human error.

Conclusions There was insufficient attention given to the operation of the Guildford Depository by the original plaintiffs, including to the subsequent use of privilege claims. Appropriate access to these documents, commensurate with the terms of legal settlements creating the collection, was critical given their public interest value for enhancing understanding of industry strategies and activities, informing of policy interventions, and for holding the industry to account. Future legal settlements should prevent defendants from subsequently withholding disclosed documents, aside from those legitimately privileged, from public view. Control of publicly disclosed documents should not be placed back into the hands of defendant tobacco companies. Plaintiffs also need to invest adequate resources into policing claims of legal privilege.

\section{INTRODUCTION}

The legal settlement in 1998 between the State of Minnesota and Blue Cross and Blue Shield of Minnesota, and defendant tobacco companies (Minnesota Consent Judgement) required the defendants to make accessible to the general public documents produced during the trial discovery process. $^{1}$ Two depositories were created for this purpose, with British American Tobacco (BAT) being permitted to locate its documents in a company operated UK-based facility known as the Guildford Depository. The Minnesota Depository remains in operation, independently administered by paralegal firm Smart Legal Assistance. BAT closed the Guildford Depository in October 2015 following expiration of the Minnesota Settlement, and a US Supreme Court decision on extraterritoriality. $^{2}$ Prior to closure, public health groups (including the current authors) secured a large proportion of Guildford documents from BAT, and made digital copies available online. However, BAT asserted privilege over 70000 documents.

Concerns about restricted conditions of access to the Guildford Depository, which contrasted with the Minnesota Depository, have been previously described. $^{3-5}$ One seminal difference is that in Minnesota, privilege and protected document claims were made in advance of public access being granted, and requested photocopies were produced to visitors quickly. At Guildford, BAT habitually took many months to process photocopy requests, with the delay ostensibly to permit review of potential privilege claims. The documents refused, based on BAT's claim of privilege or protected status, were simply omitted from production without identifying for their absence or stating any basis for the claim. These practices followed a history of tobacco companies' attempts to hide information from public scrutiny through inappropriate privilege claims. ${ }^{6}$ Before the start of Minnesota trial, internal documents provided evidence of companies abusing legal privilege by routing scientific work through lawyers as a protection from product liability lawsuits. ${ }^{7}$ During the trial, defendants asserted privilege over around 230000 documents; however, a court mandated Special Master's review found $17 \%$ of these privilege claims to be not legitimate. ${ }^{8}$ Efforts by the tobacco industry to conceal documents during the Minnesota trial through inappropriate privilege claims or document destruction are described elsewhere. ${ }^{9}$

This paper analyses whether BAT restricted subsequent public access by non-Minnesota plaintiffs to selected Guildford documents through inappropriate use of privilege claims and, if so, the nature and extent of this practice. Access to Guildford documents is especially important because analyses to date reveal unique insights into industry activities, including undue policy influence, ${ }^{10-12}$ undermining of tobacco and health science, ${ }^{13}{ }^{14}$ and complicity in cigarette smuggling. ${ }^{15-17}$ As well as raising legal questions, under the terms of the Minnesota Consent Judgement, inappropriate 
restrictions on public access to Guildford documents put at risk a unique and valuable resource for public health research and practice. $^{1819 \mathrm{i}}$

\section{METHODS}

The authors began by requesting a copy of the 'privilege log', a record maintained by BAT of Guildford Depository documents and over which the company asserted privilege or protection claims. Following opening of the depository to the public in 1999, BAT initially made the log available to visitors, as obligated under the Minnesota settlement. ${ }^{\text {ii }}$ As the BAT claims were not subject to independent verification, visitors were concerned about the potential for abuse. ${ }^{5}$ Given the difficulties for accessing the documents, ${ }^{3-5}$ the authors and others began to systematically request copies of the full set of depository materials via the Guildford Archiving Project and put these online. ${ }^{20}$ At this time, BAT withdrew access to the privilege log from the Guildford Depository viewing room. When questioned by the authors and others who had previously used the privilege log, a company representative twice denied that the log ever existed (emails from Alex Hohl, BAT to Eric LeGresley, 22 April 2009 and 14 May 2009). This stance was maintained until the representative was shown BAT internal documents attesting to its prior availability in the depository. ${ }^{21}$ Nevertheless, until the Guildford Depository was closed, the company declined to provide a copy of the privilege log to the authors.

Without access to the log and based on the company's previous record of inappropriate claims of privilege, intransigence in providing copies of documents, ${ }^{2}$ and lack of independent verification of privilege claims, the authors turned to alternative data sources. This began with an analysis of metadata from the Legacy Tobacco Documents Library (LTDL). The LTDL hosts the digital images of Guildford documents acquired by visitors to the depository, as well as a record of withheld pages and redacted parts of documents over which BAT asserted privilege. A systematic search of LTDL records identified 70519 claims of privilege by BAT over Guildford documents (emails from Rachel Taketa, UCSF to Eric LeGresley, 31 March 2008 and 23 March 2015).

To enable an assessment of the appropriateness of claims without copies of the withheld documents, the authors searched for inconsistencies of practice in the supply of Guildford documents by BAT. In most instances, the company claimed privilege on all requests for the same substantive document, and then removed all copies from the Guildford Depository. In a small subset of cases, however, inconsistencies of practice led to the withholding of a document to one party, but the provision of the same document to another.

Three approaches were used to identify such inconsistencies. First, a comparison of document request forms submitted between 1999 and 2008, by researchers from the London School

${ }^{\mathrm{i}}$ For a list of scholarly papers based on analysis of internal tobacco industry documents see the Tobacco Documents Bibliography of the Legacy Tobacco Documents Library at http://www.library.ucsf.edu/ tobacco/docsbiblio.

ii The obligation on the part of settling tobacco companies, including BAT, to provide public access to the privilege log is set out in Section VII.A.1 of the Minnesota Consent Judgement which gives access to all documents referred to in paragraph VII.A. above. The paragraph refers to "all documents, including the $4 \mathrm{~A}$ and $4 \mathrm{~B}$ indices and the privilege logs [emphasis added], which have been produced to the Plaintiffs and for which Defendants have made no claim of privilege or Category II trade secret protection.” of Hygiene and Tropical Medicine, Mayo Clinic, Rochester, Minnesota and University of California, San Francisco, USA was undertaken. Given the large volume of documents requested by these institutions over similar periods, there were likely to be cases of multiple requests for the same document. It was possible that a document refused to one institution might be produced to another or produced in a redacted form to one party, but left unredacted to another party. This approach identified 18 documents over which BAT asserted privilege inconsistently $(n=18)$.

Second, a computer search of LTDL was conducted of available documents by Bates Numbers, ${ }^{\text {iii }}$ as unique identifiers, to find instances where BAT withheld a document from one requesting party as privileged, but then produced that same document (with the same Bates Number) to another party without claiming privilege. This approach yielded 2575 cases of inconsistent privilege assertions by BAT or $3.7 \%$ of the 70519 LTDL records of privilege claims (email from Rachel Taketa, UCSF, to Eric LeGresley, 27 August 2009). A systematic sampling of every 100th document on this list was undertaken $(n=26)$.

Third, computer searches were undertaken to identify instances where BAT withheld a document from one requesting party, but a substantively identical document bearing a different Bates Number, was produced to another party. While it was recognised that inconsistent practice would yield only a small sample of documents deemed by the company as privileged and thus give only a partial view of the practice of privilege claims, the authors sought to use these examples to illustrate the need for a more formal and comprehensive review by parties of legal standing. Nineteen documents were identified as substantively identical to documents deemed legally privileged by BAT $(n=19)$ (email from Kim Klausner, UCSF, to Eric LeGresley, 13 October 2009).

To assess the appropriateness of privilege and protected document claims over these documents, the authors applied the legal definition set out in the litigation giving rise to the BAT documents. ${ }^{9}$ While details of legal privilege and protected document vary among legal systems, depending on the locally applicable statutes there are broad commonalities. ${ }^{22}$ Normally, documents obtained during pretrial discovery processes remain confidential between the plaintiff and defendant. In settling the Minnesota cost-recovery lawsuit in 1998, however, the defendants (including BAT) agreed to make publicly available documents produced on discovery during the pretrial procedures. ${ }^{1}$ Excluded from the plaintiffs and consequently, public access, from the Guildford and Minnesota depositories were: (1) documents for which the defendant tobacco company had a legitimate claim of legal privilege (primarily legal advice communicated between the tobacco company's legal counsel and the company); ${ }^{9}$ (2) materials prepared by lawyers for the defendant tobacco companies in anticipation of litigation (often called 'work product') to which a Protective Order issued by the Minnesota court applied; ${ }^{23}$ (3) documents revealing 'trade secrets' as defined by Minnesota statutes; ${ }^{24}$ and (4) certain personal documents and other material protected by statute or common law. ${ }^{1}$

Importantly, typically legal privilege afforded to solicitorclient communication is reasonably broad, but not unfettered. Under the civil procedure of many legal systems, not everything

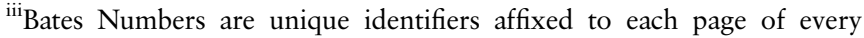
document contained within a defendant tobacco company's materials produced through documentary discovery. Pages within a document would be typically numbered sequentially.
} 
written by a solicitor is legitimately privileged. The solicitor must be acting in their capacity as legal counsel. In addition, the inclusion of information deemed privileged in an otherwise unprivileged document does not mean that the entire document is privileged. Portions of a document can be redacted (or blacked out) to remove only the portion deemed privileged while leaving the remainder for public review. At the court's discretion, documents claimed as privileged may be vetted by a court appointed Special Master. ${ }^{\text {iv }}$

Similarly, protective orders typically issued by a court do not give 'carte blanche' protection to broad classes of documents. Each class of documents to be protected from disclosure is circumscribed to protect the legitimate privacy interests of the defendant, while still meeting the plaintiff's need to access all relevant information to which there is a right of access. The authors applied the same interpretations as given above to determine the appropriateness of privilege claims asserted by BAT for the above three categories of documents from the Guildford Depository.

\section{FINDINGS}

Applying the legal definition of privilege set out in the litigation giving rise to the BAT documents, we found that 31 of 63 documents (49\%) have no apparent basis for privilege or protection claims (table 1). For these 31 documents, the 4 rationales used (see online supplementary file, table S1) are discussed below.

\section{Solicitor correspondence}

Many documents authored by BAT legal counsel had privilege claims asserted over them despite not containing legal advice or being related to anticipated litigation, which might qualify as protected work product. For instance, a letter from BAT executive and solicitor Nick Brookes ${ }^{25}$ to another company executive, regarding the company's business plans, was claimed as privileged. ${ }^{26}$ Depository staff and legal advisors vetting documents for privilege on behalf of BAT appeared to assert claims over many documents written by BAT's solicitors, regardless of content. BAT solicitors routinely placed the heading 'Privileged and Confidential' (or similar wording) on their correspondence. While the act of designating documents as privileged does not necessarily make them legally so, it appears that reviewers simply upheld these claims in some cases. For example, solicitor Nick Cannar designated a 1995 letter to Peter Clarke (BAT legal department) as 'Privileged and Secret' prior to leaving legal firm Eversheds to join BAT as in-house legal counsel. Although Cannar may have been hired by BAT to assist with litigation, this specific letter discussed practical matters regarding his move to BAT such as travel itinerary and professional status in Australia. $^{27}$

\section{Documents marked confidential or secret by BAT employees}

The documents reviewed by this paper suggest BAT employees marked some documents with headers such as 'Confidential', 'Secret' or 'Privileged'. Privilege reviewers then withheld some of these documents irrespective of the actual content and validity of the claim. This includes correspondence that did not primarily involve either a company solicitor or trade secret.

\footnotetext{
${ }^{\text {iv }}$ Citing the extraordinarily large number of documents claimed as privileged in the Minnesota tobacco litigation, a Special Master was appointed to vet privilege claims by the defendants. Minnesota $v$. Philip Morris Inc et al., Order Referring Certain Matters to a Special Master, 25 March 1997, File No. C1-94-8565, Minnesota Second District Court.
}

Table 1 Proportion of appropriate and inappropriate claims by document category

\begin{tabular}{lcclc}
\hline Document category & Total & Privileged & $\begin{array}{l}\text { Potentially } \\
\text { privileged }\end{array}$ & $\begin{array}{l}\text { Not } \\
\text { privileged }\end{array}$ \\
\hline $\begin{array}{l}\text { Inconsistent claims to } \\
\text { different Guildford }\end{array}$ & 18 & $4(22 \%)$ & $6(33 \%)$ & $8(44 \%)$ \\
$\begin{array}{l}\text { Depository visitors } \\
\begin{array}{l}\text { Inconsistent claims over } \\
\text { documents with same }\end{array}\end{array}$ & 26 & $13(54 \%)$ & $3(11 \%)$ & $10(35 \%)$ \\
$\begin{array}{l}\text { Bates Numbers } \\
\text { Inconsistent claims over } \\
\text { substantively identical } \\
\text { documents }\end{array}$ & 19 & $4(21 \%)$ & $2(11 \%)$ & $13(68 \%)$ \\
\hline
\end{tabular}

* For the 26 documents reviewed under this category, almost one-quarter contained redacted portions, with the material redacted often appearing to be handwritten margin notes. Redacting removed all indication of the content of the marginalia and the authors (for instance, Morales. ${ }^{47}$ ).

In some cases, the contents related to company operations. For example, a 1996 letter from a BAT territorial director and nonlawyer to a marketing executive, about negotiations with competitor RJ Reynolds regarding licensing negotiations in Africa, was marked 'Secret' and subsequently classified as privileged. ${ }^{28}$ In one case, the reviewer automatically asserted privilege because a document was marked as such. The document, a copy of a document by competitor Rothmans setting out questions and answers on secondhand smoke and marked by Rothmans as 'Privileged and Confidential', was subsequently withheld by BAT itself as privileged.

Even more of concern is that the documents reviewed suggest that marking of some documents as confidential, secret or privileged was intended to protect company interests. This conclusion is supported by Hammond $e t a l^{29}$ who found evidence of the destruction or relocation of research documents by BAT's affiliate, Imperial Tobacco Canada, during the early 1990s. Their review of 60 such documents, subsequently obtained from the Guildford Depository, found contents that could expose the parent company to legal liability or reputational embarrassment. This practice is confirmed in internal documents describing what BAT staff should deem as sensitive information and how privilege should be claimed to protect it. ${ }^{30-32}$ The intent, in doing so, is described in a 1988 document on Buerger's disease, a rare condition of the arteries and veins of the limbs whose sufferers are virtually all tobacco users. As well as finding a 'suitable expert' on the aetiology of the disease to prepare for potential litigation, in a letter marked 'Privileged and Confidential' to R.E. Thornton (BAT Research and Development Centre), the lawyer Andrew Foyle (Lovell, White and King) wrote of;

Our desire to create a modus operandi to ensure that legal professional privilege is not lost. Because correspondence on the subject of Buerger's disease exchanged between you and your colleagues in other companies might not be privileged, it is important that contact between the scientists should be routed through the lawyers. In addition, you should ensure that any internal memoranda written on the subject of Buerger's disease in relation to the current investigations should be captioned "Privileged and Confidential". ${ }^{33}$

While a document's contents might be considered sufficiently sensitive to limit distribution, this document is one BAT does not want others to see, rather than a document BAT has legal right to prevent others from seeing. 


\section{Secondhand recitation of legal opinions}

Some documents reviewed include reference, by non-lawyer BAT employees, to legal opinions previously provided by legal counsel but without a copy of that opinion. ${ }^{34}$ These are not documents produced by a non-lawyer, demonstrably at the behest of a lawyer in anticipation of litigation, which might be justifiably privileged as work product. Rather, these consist of the subsequent use by non-lawyers of information or opinions previously stated, with no apparent action on the part of legal counsel either in directing or participating in the creation of the document. For instance, a 1994 'Restricted' note to the BATCo Executive Committee, claimed as privileged, included a one sentence summary of the opinion of BAT legal counsel regarding the purchase of a majority interest in a Trinidadian tobacco company. The opinion is not attached nor is it quoted verbatim. Neither of the authors of the note was apparently the author of the legal opinion referred to, and neither was acting in the capacity of legal counsel. This is secondhand commentary and, in most instances, unverifiable as an accurate summary of the views espoused by legal counsel. This practice was inappropriate because legal privilege applies to communication of a legal opinion between legal counsel and client, but not to the subsequent and independent use by the client of the views expressed in that legal opinion. A document may be deemed privileged if it involved correspondence with another legal counsel (such as telling new legal counsel the views of prior counsel), but that privilege arises due to the latter communication, not as a holdover from the initial legal opinion. Thus, there is no reason to distinguish a broad rephrasing of a legal opinion by the client from any other communication to the client. For example, a claim was asserted over a draft letter by BAT's Public Affairs Manager to be sent to 'The Guardian' newspaper. ${ }^{35}$ The letter did not constitute legal advice and was apparently not written by BAT legal counsel, although a copy was sent to a BAT solicitor and several marketing staff and scientists.

\section{Personal documents}

The Protective Order in the Minnesota tobacco trial permitted the withholding of private papers that constituted 'protected information under applicable statutory or common law'. ${ }^{36}$ There was no presumption of confidentiality, and the onus of proof was on the party seeking to withhold the documents. This onus required an independent document-by-document assessment, and did not allow for a blanket policy of removing material simply because, for example, it bore home letterhead.

This review found that senior BAT executives sometimes used company time and resources to address personal matters. Much of this type of correspondence is unlikely to interest public health researchers because they have no bearing on BAT activities. However, those vetting BAT documents for privilege seemed to be taking a broad view on which personal papers might be deemed as privileged by seemingly removing everything written on home letterhead irrespective of its contents. In the authors' view, documents on personal letterhead should only be protected and, therefore, withheld from public production when they deal solely with personal matters not involving BAT assets or other employees. For instance, an invoice to an executive regarding his children's school fees would appropriately be protected. ${ }^{37}$ In contrast, the authors do not consider a document providing home contact information for a senior BAT executive to a foreign BAT company, ${ }^{38}$ or a letter to a country club transferring membership from one BAT executive to another as warranting protection. ${ }^{39}$ The blanket protection of such documents also creates an opportunity to hide sensitive material simply by placing correspondence on home letterhead. This practice is referred to by Phillip Morris executive Thomas Osdene in a handwritten note regarding the destruction of potentially sensitive documents relating to the industry-funded Institute for Biological Research (INBIFO): "If important letters or documents have to be sent, please send to home-I will act on them and destroy". ${ }^{40}$

\section{DISCUSSION}

This review finds that BAT made questionable privilege or document protection assertions in almost half $(49 \%)$ of the documents reviewed. This higher rate of inappropriate claims, compared to the $17 \%$ of documents found by the Special Master of the Minnesota trial (email from Rachel Taketa, UCSF, to Eric LeGresley, 27 August 2009), can be attributed to two main factors.

First, the methodology used to identify and access documents, over which BAT asserted privilege, may yield a higher rate of inappropriate claims. Given 6-7 million pages of documents in the Guildford Depository, and 70527 documents over which BAT asserted privilege or protection, a comprehensive review of each claim is beyond the scope of this paper. Even during the multibillion dollar Minnesota trial, only spot checks were undertaken to assess the privilege claims of defendants. ${ }^{9}$ When documentation produced during discovery totalled tens of millions of pages, the courts and plaintiffs were understandably incapable of vetting each to ensure that documents were properly disclosed.

The unilateral withholding of documents by BAT means that the authors do not have access to most of the privileged documents for review purposes. As a result, the data set used to assess the veracity of claims is necessarily selective and limited. For documents that the authors were able to obtain indirectly, it is recognised that there is selection bias owing to the actions of BAT legal counsel and/or privilege reviewers. While the Special Master's report had access to all of the documents produced and, therefore, could systematically assess a representative sample, this analysis reviews only those documents where there was inconsistent treatment by BAT. Given that problems with the application of legal privilege could be a major factor leading to a document being treated in an inconsistent manner and thus brought to the authors' attention, it is recognised that a far higher percentage of these documents may have had privilege inappropriately asserted.

A second factor is BAT's preferential treatment under the Minnesota Consent Judgement. Although inappropriate claims of privilege or protection could be made by any of the Minnesota trial's defendants, we contend that there has been greater potential for abuse as a result of BAT being treated differently. BAT was added as a defendant in the Minnesota litigation comparatively late in the process. To reduce further delay, unlike other defendants, BAT was permitted to produce potentially relevant files rather than required to comb through files to produce only documents that were relevant to specific questions posed. The result was a BAT depository organised by file rather than document. BAT was also treated as a special case in the Minnesota settlement, including being given permission to retain file-level organisation, when discovered documents were 
transformed into a publicly accessible depository. Finally, BAT was permitted to create and operate its own depository in the UK, thus asserting de facto control over the housing and management of the collection. ${ }^{\mathrm{v}}$ This control of the depository enabled BAT to remove from public view and deny public access to the privilege log contrary to its legal obligations. In its place, the company offered a file-by-file listing (by Bates Number) of the pages removed under a privilege claim (A Hohl, personal communication, 2009).

Given a history of intransigence in providing public access to the Guildford Depository, ${ }^{4}$ this paper argues that questionable claims of legal privilege and protection, and lack of independent oversight of BAT actions undermined the intent of the Minnesota settlement to make the company more transparent and accountable. ${ }^{41}$ Internal tobacco industry documents to date, as intended by the Minnesota plaintiffs, have proven to be a unique data source for public health researchers to understand the inner workings of tobacco companies. ${ }^{18}$ Addressing restrictions, including inappropriate privilege claims, remains vital to the ability of the public health community to adopt effective regulation of the industry in future.

Importantly, this paper's findings should not be discounted either because the number of documents available for review was small or because the substance of the documents reviewed, taken in isolation, seem of little import to public health. Until a comprehensive review of the 70527 documents over which BAT is claiming privilege or protected status is independently verified, their true value to public health will remain unknown. The high incidence of questionable claims identified in this review suggests that, at the very least, further review is warranted. While BAT benefited most directly from the inappropriate use of privilege over Guildford documents, it is instructive to reflect on what transpired during the Minnesota trial so as to reduce industry capacity to assert inappropriate privilege claims in future. Notwithstanding the groundbreaking role of the Minnesota plaintiffs, the fact that the public value of these documents was not yet fully understood and that BAT's questionable practices were yet to be exposed, the terms setting out the conditions for creating and managing the Guildford Depository were flawed. While the Minnesota plaintiffs had access to a privilege log created by the defendants, in many instances, the information presented was so vague that it was of little help in assessing the merit of the privilege claim. The court roundly rebuked the defendants for this. ${ }^{\mathrm{vi}}$ If the Minnesota court was previously concerned that generalised titles in a $\log$ were insufficient to assess whether a document might be legitimately claimed as privileged, there should have been greater concern with BAT using a Bates Number range as the sole information provided for Guildford documents. Furthermore, it should never have been agreed to permit BAT

\footnotetext{
${ }^{\mathrm{v}}$ Reinforcing the special treatment afforded to BAT, a Supreme Court decision (Morrison v National Bank Australia Ltd. 561 US (2010)) rejecting the "effects" test for extraterritoriality, led Judge Gladys Kessler to rule that this, in turn, invalidated her ruling of BAT's liability under the Racketeer Influenced and Corrupt Organizations Act (RICO) including requirements on the future disclosure of industry documents. USA v Philip Morris et al. Memorandum Opinion, Civil Action No. 992496 (GK), 28 March 2011.

${ }^{v i}$ The Minnesota court stated its concern as follows: "[T]he Court is concerned and cautions the parties to provide sufficient information in their privilege logs so that a reasoned decision can be made without in camera review of an unreasonable percentage of documents..." State ex rel. Humphrey v. Philip Morris Inc., No. C1-94-8565, (MN Dist. Ct., Nov. 8, 1996).
}

to independently create and control the Guildford Depository. Regardless of a desire to conclude long, complex, and costly litigation, BAT document production should have been fully vetted prior to concluding the case.

These lessons remain critical given the ongoing tobacco litigation in several jurisdictions in the USA and elsewhere. The requirement, under the 2006 final settlement of the US Federal government lawsuit under the Racketeer Influenced and Corrupt Organizations (RICO) Act against the tobacco industry, to continue to publicly disclose (non-privileged and nonconfidential) internal documents produced in US-based smoking and health litigation until $2021^{42}$ means that new industry document collections should become publicly accessible. The subsequent 2011 ruling that BAT is not subject to the Court's jurisdiction under the RICO Act and that the Final Order, therefore, does not cover BAT $^{43}$ means differential treatment once again for the company. Ensuring the complete integrity and maximum utility of internal industry document collections will require focusing on securing access to, and preserving the full integrity of these collections.

\section{CONCLUSION}

While tobacco litigation is primarily framed in terms of providing legal liability for ill-health in individuals and populations, recovering healthcare costs, and penalising companies for misconduct, the public disclosure of tens of millions of pages of internal tobacco industry documents was an equally significant outcome of legal proceedings. The intent of the Minnesota Consent Judgement, in putting these documents in the public domain, was to increase the accountability of the tobacco industry and prevent future corporate misbehaviour. The political and legal importance of the documents is now well understood, and industry documents have been frequently used to buttress policy interventions, shape public opinion and support further litigation. Equally important, however, are the public health benefits from industry documents, not only as a unique data source to support efforts to strengthen tobacco control policies, but for providing critical insights into the inner workings of a large and powerful industry with direct and substantial impacts on health. ${ }^{44}$ Such insights, in turn, offer further lessons for the regulation of other key industries that impact on the broad determinants of health. ${ }^{45} 46$

This paper argues that alongside document destruction and conditions of access to the Guildford Depository, BAT asserted privilege and protection claims inappropriately in order to further hinder public access. Fulfilment of the stipulations under the Minnesota Consent Judgement has fallen short because of the failure to require independent operation of the depository

\section{What this paper adds}

This research suggests British American Tobacco hindered access to the Guildford Depository through questionable privilege claims. There was need for more effective oversight of document discovery, as well as of the legal procedures, that challenged the tobacco industry's subsequent withholding of documents without legitimate claims of privilege. Measures to ensure ongoing and full access to internal tobacco industry documents, commensurate with the terms of legal settlements creating such collections, should be an important consideration in the future settlement of tobacco litigation. 
and sufficient oversight. Once the Minnesota settlement was concluded and about US $\$ 6$ billion paid to state coffers, the ongoing operation of a document depository, located over $6000 \mathrm{~km}$ away in southern England, understandably may not have been of utmost concern to plaintiffs. The findings of this paper suggest the need to take a keener interest in ongoing public access conditions in future legal settlements, including effective oversight of document discovery and legal procedures for challenging the tobacco industry to disclose documents withheld without legitimate claims of privilege.

Acknowledgements The authors acknowledge the assistance of Ela Gohil (LSHTM) for assisting in the analysis of Guildford Depository document requests, and Rachel Taketa (University of California, San Fransisco Library) for calculating the total number of BAT documents withheld under privilege claims and potential

inconsistencies of practice by the company. The authors also thank Anna Gilmore for commenting on an earlier draft of this paper.

Contributors EL and KL conceptualised and designed the study, and undertook data collection and analysis. EL wrote the intial draft, and KL undertook subsequent rewriting and revisions. Both authors contributed to revising the paper following peer review and final approval of the published version.

Funding This work was supported by the National Cancer Institute, US National Institutes of Health (Grant number R01 CA091021).

Competing interests $\mathrm{KL}$ and colleagues led efforts at the London School of Hygiene \& Tropical Medicine to acquire a complete set of copies of materials held at the Guildford Depository run by British American Tobacco. She received funding from the Wellcome Trust, Nuffield Trust, Cancer Research UK and Health Canada for these efforts.

Provenance and peer review Not commissioned; externally peer reviewed.

Data sharing statement No additional data are available.

Open Access This is an Open Access article distributed in accordance with the Creative Commons Attribution Non Commercial (CC BY-NC 4.0) license, which permits others to distribute, remix, adapt, build upon this work non-commercially, and license their derivative works on different terms, provided the original work is properly cited and the use is non-commercial. See: http://creativecommons.org/ licenses/by-nc/4.0/

\section{REFERENCES}

1 Minnesota v. Philip Morris Inc et al., Settlement Agreement and Stipulation for Entry of Consent Judgment, 8 May 1998, File No. C1-94-8565, Minnesota Second District Court. http://www.library.ucsf.edu/sites/all/files/ucsf_assets/mnconsent.pdf

2 BAT. British American Tobacco to close Guildford Depository. News Release 31 July 2015. http://www.bat.com/group/sites/UK__ 9D9KCY.nsf/vwPagesWebLive/ D09YXBZF?opendocument

3 Collin J, Lee K, Gilmore AB. Unlocking the corporate documents of British American Tobacco: an invaluable global resource needs radically improved access. Lancet 2004;363:1746-7.

4 Muggli ME, LeGresley EM, Hurt RD. Big tobacco is watching: British American Tobacco's surveillance and information concealment at the Guildford Depository. Lancet 2004;363:1812-19.

5 LeGresley EM, Muggli ME, Hurt RD. Playing hide-and-seek with the tobacco industry. Nicotine Tob Res 2005;7: 27-40.

6 Guardino SD, Daynard RA. Tobacco Industry lawyers as 'disease vectors'. Tob Control 2007;16:224-8.

7 Hanauer $\mathrm{P}$, Slade J, Barnes DE, et al. Lawyer control of internal scientific research to protect against products liability lawsuits. The Brown and Williamson documents. JAMA 1995;274:234-40.

8 Gehan MW. Report of Special Master: findings of Fact, Conclusions of Law and Recommendations Regarding Non-Liggett Privilege Claims, Minnesota v. Philip Morris Inc et al., 10 February 1998, File No. C1-94-8565, Minnesota Second District Court.

9 Ciresi M, Walburn RB, Sutton T. Decades of deceit: document discovery in the Minnesota Tobacco Litigation. William Mitchell Law Rev 1999;25:477-510.

10 Gilmore AB, McKee M, Collin J. The invisible hand: how British American Tobacco precluded competition in Uzbekistan. Tob Control 2007;16:239-47.

11 Patel P, Collin J, Gilmore AB. "The law was actually drafted by us but the government is to be congratulated on its wise actions": British American Tobacco and public policy in Kenya. Tob Control 2007;16:e1.

12 Holden C. Lee K, Fooks G, et al. The Impact of Regional Trade Integration on Firm Organization and Strategy: British American Tobacco in the Andean Pact. Bus Polit 2010;12:Article 3:1-30.
13 Muggli ME, Lee K, Gan Q, et al. "Efforts to Reprioritise the Agenda" in China: British American Tobacco's efforts to influence public policy on secondhand smoke in China. PLoS Med 2008;23:1729-69.

14 Petticrew MP, Lee K. The "father of stress" meets "Big Tobacco": Hans Selye and the tobacco industry. Am J Public Health 2011;101:411-8.

15 Collin J, Legresley E, MacKenzie R, et al. Complicity in contraband: British American Tobacco and cigarette smuggling in Asia. Tob Control 2004;13(Suppl 2):ii104-11.

16 Lee K, Collin J. "Key to the future"': British American Tobacco and cigarette smuggling in China. PLoS Med 2006;3:e228.

17 Legresley E, Lee K, Muggli ME, et al. British American Tobacco and the "insidious impact of illicit trade" in cigarettes in Africa. Tob Control 2008;17:339-46.

18 Hurt RD, Ebbert JO, Muggli ME, et al. Open doorway to truth: legacy of the Minnesota Tobacco Trial. Mayo Clin Proc 2009:84:446-56.

19 Lee K, Gilmore AB, Collin J. Looking inside the tobacco industry: revealing insights from the Guildford Depository. Addiction 2004;99:394-7.

20 Hopkin M. Researchers seize moment to make tobacco data public. Nature 2004;429:492.

21 Anonymous. Guildford Depository Public Visits, Visitors review files sub-process, January 2000, version 1.0, 25 July 2000. BAT, Bates No. 321405582. Minnesota Tobacco Document Depository. http://legacy.library.ucsf.edu/tid/bfs97a99 (accessed 10 Oct 2010).

22 Rice P. For an overview of the concepts underlying solicitor-client privilege from an American perspective see. Attorney-Client Privilege in the United States. 2nd edn. Minnesota: West Group, 1999.

23 Minnesota v. Philip Morris Inc et al., Order Regarding Privilege and the Crime-Fraud Exception and Setting Forth Procedures to Determine Privilege Beginning with the Liggett Documents, 9 May 1997, File No. C1-94-8565, Minnesota Second District Court.

24 Minnesota v. Philip Morris Inc et al., Protective Order, 16 June 1995, File No. C1-94-8565, Minn Second District Ct., 10.4 TPLR 2.104, at paras. 5 and 21.

25 http://www.tobacco-on-trial.com/profiles/witnesses/brookes-nicholas-g

26 See Brookes N. Letter to Ulrich Herter, 6 October 2000, British American Tobacco Bates No. 325039684. http://legacy.library.ucsf.edu/tid/rcn53a99/pdf (accessed 10 Oct 2015).

27 See Cannar N. Letter to P.L. Clarke, 14 December 1995, British American Tobacco, Bates No. 700452717. http://legacy.library.ucsf.edu/tid/ubi75a99/pdf (accessed 10 Oct 2015).

28 Johnston T. Memo to J. Winebrenner, 12 December1996, British American Tobacco, Bates No. 321503335-3336. http://legacy.library.ucsf.edu/tid/ope51a99/pdf (accessed 10 Oct 2015).

29 Hammond D, Chaiton M, Lee A, et al. Destroyed documents: uncovering the science that Imperial Tobacco Canada sought to conceal. CMAJ 2009;181:691-8.

30 Meltzer J. Letter from Ogilvy Renault, 5 June 1992, British American Tobacco, Bates No. 202313418-3421. https://industrydocuments.library.ucsf.edu/tobacco/docs/ \#id=rfwk0194 (accessed 14 Oct 2015).

31 Hardwick M. Information, Materials, For the USA, 30 January 1985, British American Tobacco, Bates No. 109968446-8447. http://legacy.library.ucsf.edu/tid/ spl00a99/pdf? search=\%22109968446\%22 (accessed 14 Oct 2015).

32 Hardwick M. Material for Brown \& Williamson, 9 January 1985, British American Tobacco, Bates No. 107444869. http://legacy.library.ucsf.edu/tid/ggy34a99/pdf? search $=\% 22107444869 \% 22$ (accessed 14 Oct 2015).

33 Foyle A. Buerger's disease [Letter to RE Thornton], 21 March 1988, British American Tobacco, Bates No. 300517039-7040. http://legacy.library.ucsf.edu/tid/ mov66b00/pdf (accessed 10 Oct 2015).

34 See Pilbeam RH, Clarke PL. Recommendation to the Chief Executive's Committee, 18 November 1994, British American Tobacco, Bates No. 202718107. http://legacy. library.ucsf.edu/tid/ora26a99 (accessed 10 Oct2015).

35 Cannon M. Note Regarding BAT's Policy (draft letter to The Guardian newspaper), undated, British American Tobacco, Bates No. 104585326. http://legacy.library.ucsf. edu/tid/udr86b00/pdf (accessed 10 Oct 2015).

36 Minnesota v. Philip Morris Inc et al., Protective Order, 16 June 1995, File No. C1-94-8565, Minnesota Second District Ct., 10.4 TPLR 2.104.

37 Anonymous. Invoice from Bryanston School fees for student William Rowlands-Rees, 15 Dec 1993, British American Tobacco, Bates No. 301729539. Minnesota Tobacco Document Depository. http://legacy.library.ucsf.edu/tid/mws77a99 (accessed 10 Oct 2015).

38 See Macey J. to Ho E. Facsimile regarding contact information for Paul Adams, 1 December 1993, British American Tobacco, Bates No. 500015751. http://legacy. library.ucsf.edu/tid/aev17a99 (accessed 10 Oct 2015).

39 Adams PN. [Letter to D. Freemantle regarding Mill Ride Golf Club annual subscription fee for the year 1993-1994], 22 December 1993, British American Tobacco, Bates No. 500015728. http://legacy.library.ucsf.edu/tid/gdv17a99 (accessed 10 Oct 2015).

40 Osdene TS. (n.d.). Handwritten note. Philip Morris, Bates No. 1000130803. http:// legacy.library.ucsf.edu/tid/imq10j00/pdf (accessed 10 Oct 2015).

41 Muggli ME, Crystal HM, Klausner K. Transparency as a remedy against racketeering: preventing and restraining fraud by exposing Big Tobacco's dirty secrets. Tob Control 2015;24:514-18 
42 United States v. Philip Morris USA, Inc. Final Judgment and Remedial Order. 17 August 2006. http://www.library.ucsf.edu/sites/all/files/ucsf_assets/final_judgment_ order.pdf (accessed 10 Oct 2015).

43 United States v. Philip Morris USA, Inc. Document No. 5901. Memorandum Opinion. 28 March 2011. http://www.library.ucsf.edu/sites/all/files/ucsf_assets/ DN5901_03-28-2011.pdf (accessed 10 Oct 2015).

44 Bero L. Implications of the tobacco industry documents for public health and policy. Annu Rev Public Health 2003;24:267-88.
45 Brownell KD, Warner KE. The perils of ignoring history: Big Tobacco played dirty and millions died. How similar is Big Food? Milbank Q 2009;87:259-94.

46 Shamasunder B, Bero L. Financial ties and conflicts of interest between pharmaceutical and tobacco companies. JAMA 2002;288:738-44. http://dx.doi.org/ 10.1001/jama.288.6.738

47 Morales L. Objeto y Asignacion de Capital a la Sucursal en Gestion, Cover Letter, British American Tobacco, Bates No. 321620576. http://legacy.library.ucsf.edu/tid/ fgp93a99/pdf (accessed 10 Oct 2015). 